\title{
A LIQUIDAÇÃO DAS TERRAS PÚBLICAS NO BRASIL: CONTEXTOS, PRETEXTOS E PASSIVOS TERRITORIAIS EM FACE DA LEI 13.465/2017
}

\author{
THE LIQUIDATION OF PUBLIC LAND IN BRAZIL: TERRITORIAL \\ CONTEXTS, PRETEXTS AND LIABILITIES IN LIGHT OF LAW 13.465/2017
}

\author{
LA LIQUIDACIÓN DE LAS TIERRAS PÚBLICAS EN \\ BRASIL: CONTEXTOS TERRITORIALES, PRETEXTOS Y \\ RESPONSABILIDADES A LA LUZ DE LA LEY 13.465/2017
}

Eliane Tomiasi Paulino - Universidade Estadual de Londrina - Londrina - Paraná - Brasil
eliane.tomiasi@uel.br

\section{Resumo}

As profundas modificações sobre a constituição da propriedade privada no Brasil impostas pela Lei 13.465/2017 demandam reflexões sobre suas características, suas implicações e os processos que a antecederam. Sancionada um dia antes de ser votado o parecer da Comissão da Câmara dos Deputados que bloquearia a autorização para o Supremo Tribunal Federal investigar crimes de Michel Temer, Presidente da República, essa medida revela o contexto das oportunidades de classe que os ruralistas conseguiram angariar para si. A isso se atribui duas conquistas estruturais concomitantes aqui analisadas: 0 ataque ao legado da política de assentamentos no Brasil, mediante a determinação de emancipação compulsória de qualquer um deles implantados há mais de 15 anos; e a premiação aos grandes invasores de terras públicas, denominados grileiros, do definitivo ato do reordenamento territorial, o título de propriedade, mediante exclusividade de comprá-las do Estado a preços irrisórios. Ao problematizar a chancela jurídica da invasão de terras por meio da célere titulação como culminância de um processo persistente, porém aprofundado neste milênio, perscrutase determinações e implicações da renúncia à primazia do interesse difuso em favor da capacidade de rapina segundo a perspectiva do trunfo de classe em seu apogeu no país.

Palavras-chave: Grilagem, regularização fundiária, reforma agrária, passivos territoriais.

\section{Abstract}

The profound changes to the constitution of private property in Brazil imposed by Law 13.465/2017, calls for reflections on its characteristics, its implications, and the processes that preceded it. Sanctioned one day before the House of Representatives Committee's opinion was voted, this would have blocked the Federal Supreme Court's authorization to investigate Michel Temer's, President of the Republic, crimes. This measure reveals the context of class opportunities that large landowners were able to mobilize in their own interest. For this, two concomitant structural conquests analyzed in this work are attributed: the attack of Brazil's land settlement policy and its legacy, by determining the compulsory emancipation of any settlements that are more than 15 years old, and the extension of the definitive act of territorial reordering, the property title, to large invaders of public lands, called land grabbers (grileiros), who acquire exclusive rights to purchase the land from the state at extremely low prices. Positioning judicial recognition of land invasion through the expedient formalization of land titles as the culmination of a persistent process that deepens in this millennium, one examines the determinations and implications of renouncing the primacy of public interest in favor of the capacity to plunder in accordance to the class asset perspective that finds its heyday in Brazil.

Keywords: Land grabbing, land regularization (regularization of public lands stolen), agrarian reform, territorial liabilities. 
Eliane Tomiasi Paulino

\section{Resumen}

Los cambios profundos en la constitución de la propiedad privada en Brasil impuestas por la Ley 13.465/2017 requieren reflexiones sobre sus características, sus implicaciones y los procesos que la precedieron. Sancionado un día antes de la Comisión en la Cámara de Representantes bloquear la autorización del Supremo Tribunal Federal para investigar los crímenes de Michel Temer, Presidente de la República. Esa medida revela el contexto de oportunidades de clase que los grandes terratenientes consiguieron movilizar en su propio interés. A eso se atribuye dos conquistas estructurales concomitantes aquí analizadas: el ataque al legado de la política de asentamientos en Brasil, a través de la determinación de emancipación compulsoria de cualquier uno de ellos, implantados hace mas de 15 años; $y$, al mismo tiempo, la extensión del derecho de propiedad para tierras públicas invadidas mediante autorización de exclusividad para comprar a precios extremadamente bajos. Al problematizar la legalización de la invasión a través de la obtención rápida del títulos de propiedad de tierras como fin de un proceso persistente que, sin embargo, se agudiza en este milenio, se estudian determinaciones e implicaciones de la renuncia a la primacía del interés confuso a favor del saqueo según la perspectiva del triunfo de clases privilegiadas en el país.

Palabras clave: Acaparamiento de tierras, ordenamiento agrario inconstitucional, reforma agraria, pasivos territoriales.

\section{Introdução}

Na antevéspera do natal de 2016, Michel Temer enviou ao congresso a Medida Provisória 759 com regime de urgência. Como matéria de rito sumário, foi blindada com supressão de trâmites e escapou à submissão em comissões técnicas que pudessem atestar constitucionalidade e pertinência legal mínima, ritos próprios das leis ordinárias.

Em 4 meses, passou pelas votações na Câmara dos Deputados, foi enviada ao Senado da República com o oferecimento de 732 emendas, culminando num parecer que resultou no Projeto de Lei de Conversão (PLV) número 12, de 04 de maio de 2017, vindo à sanção presidencial no dia 11 de julho de 2017, como Lei número 13.465/2017. Com ela, foram revogados ou alterados, em parte, o teor de nada menos que 20 Leis, 1 Medida Provisória e 4 Decretos-Leis.

Celeridade ímpar e adendos significativos ao inicialmente proposto pelo Presidente da República reforçariam os objetivos originários: a liquidação do legado da política de assentamentos no país, paralelamente à dilapidação do patrimônio constituído pelas terras públicas, por meio da ampliação das oportunidades para a grilagem, um crime por meio do qual o bem comum pode ser convertido no ativo mobilizável mais nobre e indestrutível no capitalismo, o título de propriedade fundiária.

A acumulação primitiva tal qual fora identificada por Marx (1974) e que se renova no processo permanente de produção de capital teria aqui um capítulo à parte, por conta da sua densidade traduzida na extensão do 
território atingido e consequente possibilidade de realização extraordinária de renda capitalizada da terra.

A justificativa presidencial foi a urgência em solucionar um ato proveniente da mesma coalizão de forças que impôs o bloqueio ao Programa Nacional de Reforma Agrária e de um amplo espectro de políticas públicas a que esse público tinha acesso. O instrumento foi o Processo 517/2016-0 do Tribunal de Contas da União, motivado por supostas irregularidades cometidas tanto pelo Instituto Nacional de Reforma Agrária (INCRA), quanto pelos assentados. A fragilidade jurídica de ambos os elementos, assim como o conteúdo da matéria, está consubstanciada na Nota Técnica 01/2017 da Procuradoria Geral da República (Brasil, 2017b), emitida pelo Grupo Terras Públicas e Desapropriação, da Câmara de Coordenação e Revisão do Ministério Público, responsável por fornecer subsídios para a fiscalização da gestão das terras públicas e da ocupação fundiária em escala nacional.

A instituição de "mecanismos para aprimorar a eficiência dos procedimentos de alienação de imóveis da União” (Brasil, 2009b), como se poderá ler na súmula da Lei, nada mais é do que a demolição de cláusulas constitucionais pétreas fundadas no princípio da igualdade de todos perante a Lei e na função social da terra, para ser fiel à distinção qualitativa feita por Marés (2003), em relação ao conteúdo classista próprio da expressão função social da propriedade prevista na Constituição. Bem ou mal, sobre essa salvaguarda expressa foram construídos os diagnósticos, as interpretações e os planos de ordenamento fundiário destroçados pela mudança legal em apreço, a começar pela Lei de Terras de 1850, quando foram estabelecidos os critérios para a constituição da propriedade privada no país.

O redesenho das interdições de classe para o acesso ao solo urbano e rural é de tal ordem que, por ora, não está claro como se dará sua aplicação, situação que só o tempo poderá revelar. Mas nem por isso é preciso furtar-se à análise, mesmo que seja para uma indicação ao futuro: que jamais se renuncie, enquanto coletividade, ao comprometimento com a constituição e com a vigilância diuturna sobre suas Casas de Leis.

A inconciliabilidade dos interesses nos contratos que regem uma sociedade de classes tem nas evidências aqui evocadas um exemplo singular: não bastaria ao latifúndio sair fortalecido, como o foi, pelo simples fato de que, mesmo vulnerabilizado, o campesinato, particularmente o público da reforma agrária e da regularização fundiária constitucional, 
pode seguir como presença incômoda a acusar outras possibilidades econômicas e civilizacionais para o Brasil.

O texto da Lei Agrária (Lei 8.629/1993) regulamentou os preceitos da Constituição de 1988, no tocante à classificação da propriedade familiar que havia preservado, com distorções, o critério de viabilidade correlacionada ao tamanho mínimo de uma unidade econômica agrícola, determinado pelo Estatuto da Terra (Lei 4.504/1964). Para Talaska (2016), o simples fato de ter sido possível sancioná-la em 1993 já seria um saldo positivo, considerando o contexto de derrotas dos movimentos sociais impostos pelos ruralistas e que está expresso no capítulo constitucional da ordem agrária. Depreende-se que foi a derrota momentânea sofrida pelas oligarquias, em meio ao processo de impeachment de Fernando Collor de Melo, que a explica.

Ainda assim, ao preço de importante amputação: o reconhecimento expresso de duas categorias de propriedades apenas, as pequenas e as médias com, respectivamente, de um a quatro e de quatro a quinze módulos fiscais. Evidência de que os abalos na hegemonia de classes não foram suficientes para anular o saldo vitorioso expresso na Carta Constitucional, pois tanto o minifúndio quanto o latifúndio sumiram do léxico normativo, estratégia que se mostraria útil contra a pauta política da reforma agrária.

Eis que a nova redação dada pela Lei de Temer elimina essa sutileza pela raiz, operando não mais para a omissão da minifundiarização, mas pela eliminação do critério de módulo fiscal para classificar propriedades rurais viabilizáveis. Isso poderia ser um detalhe, se não fosse o fato de ser o módulo fiscal o parâmetro definidor da extensão mínima de área rural considerada suficiente para uma família trabalhar com possibilidade de progresso social e que, aliás, é a diretriz para a imissão do título como imóvel rural.

Doravante, considera-se ser possível viver da agricultura com menos terras do que antes, permitindo-se a um país de tão vastas dimensões um processo de minifundiarização ainda mais profundo. Eis o sentido de eliminar o módulo fiscal para a tipificação da pequena propriedade, adotando-se em seu lugar a Fração Mínima de Parcelamento, embora tal critério somente possa ser aplicável a imóveis dedicados à produção hortigranjeira que, pela natureza da atividade, pode se viabilizar em frações diminutas de terra. 
Medida diametralmente oposta está concatenada a tal propósito, pois a nova Lei torna impune e premia exponencialmente os invasores de grandes parcelas de terras públicas, agora equiparadas aos diminutos lotes da reforma agrária. Os beneficiários somente são agraciados em vista da pobreza pronunciada, da tradição campesina e, não raro, depois de prolongada batalha pela integridade física e social típica dos acampamentos de sem terra. Na prática, passa a vigorar tratamento igualitário para grileiros e assentados, devidamente respaldados pela Portaria INCRA 199/2017, a qual atualiza a Tabela de Valores da Terra Nua das terras da União e determina a indistinção, para efeito de enquadramento para a Concessão do Direito Real de Uso. É por meio desse procedimento que a terra pública converter-se-á em particular, garantida a emissão do título de propriedade.

A conduta discricionária dos mandatários do Estado notoriamente latifundista o explica, a julgar pelos critérios utilizados pelo Tribunal de Contas da União, via Acórdão 775/2016. A pretexto de indícios de irregularidade no Programa Nacional de Reforma Agrária, dentre os quais o suposto enriquecimento ilícito de nada menos que $578 \mathrm{mil}$ famílias beneficiárias, em abril de 2016, foi determinada a suspensão indiscriminada: I) dos processos de seleção de novos beneficiários; II) do assentamento de novos beneficiários já selecionados; III) dos pagamentos de créditos da reforma agrária devidos; IV) do acesso às políticas públicas como o Garantia Safra, o Bolsa Verde, o PRONERA, o Programa de Aquisição de Alimentos, o Programa de Assistência Técnica e Extensão Rural e o Programa Minha Casa Minha Vida Rural, dentre outros. O teor do Acórdão Brasil (2016, p. 32-33) que, posteriormente, suspenderia temporariamente a medida, fala por si:

O que não se pode é conceder terra a pessoas que não se enquadrem nos requisitos do PNRA, como por exemplo, conceder terra da reforma agrária a pessoas abastadas, que possuam outras rendas consideráveis, e não dependam, em realidade, da terra, para sobrevivência, ou como atividade essencial ou principal. Os indícios apontados deverão, oportunamente, ser objeto de verificação por parte do Incra [...]. Após o período de suspensão da cautelar haverá automaticamente novo bloqueio. [...] não se pretende a exclusão de qualquer beneficiário do quadro de indícios, sem uma análise e verificação pormenorizada. Os indícios permanecerão como indicativos a serem investigados pelo Incra. 
Ocorre que os atos tipificados como crime para o público da reforma agrária, como conceder terra a pessoas abastadas e as que não a tem como atividade essencial, estão autorizados para os invasores, pois a extensão regularizável atinge 2.500 hectares, admitindo-se como prova de posse mansa e pacífica não apenas o uso indiscriminado do trabalho alheio para comprovação da exploração direta em terras pertencentes à União, quanto à gestão por terceiros dos negócios ali empreendidos, dentre os quais até mesmo a exploração madeireira, leia-se desmatamento.

Assim, o princípio da função social como legitimador da posse cede passagem à invasão em ampliada concretude, à medida que o domínio sobre a terra se desvincula da sua condição sine qua non: a oportunidade de viver do trabalho próprio. Passa a vigorar o critério de posse como um meio de explorar o trabalho alheio para, por meio dele, consumar a apropriação das riquezas florestais e da terra que as comportam.

E pensar que a expressão invasão vem sendo invariavelmente evocada ante ações de trabalhadores que efetivamente a ocupam, fazendo do domínio infecundo o lugar para a realização do trabalho familiar que provê comida aos seus e à sociedade, ainda que em escassa medida. Nisso resume-se o sentido da exploração direta, não obstante a engenharia linguística da nova Lei que pune os despossuídos para homologar o direito de locupletação dos aquinhoados. Analisar suas condicionantes e implicações, numa situação característica de liquidação do patrimônio nacional é o objetivo deste texto.

Os mecanismos de transmissão das terras públicas para particulares no contexto da reinvenção de privilégios de classe

Embora o senso comum leve a crer que a reforma agrária resuma-se à doação de terras para oportunistas, o fato é que ela consiste numa política de concessão de uso, permanecendo como terra pública até que o Estado considere haver aí efetiva emancipação econômica a quem foi dada essa permissão, momento em que o assentamento ganha o status de consolidado. Quando isso ocorre, todo assentado deverá efetuar o pagamento pelo respectivo lote, com cálculo baseado no valor da terra nua, definido pela tabela referencial já mencionada. É precisamente nisso que consiste a Concessão do Direito Real de Uso. 
Trata-se de uma possibilidade de ordenamento que exigiu a alteração de uma cláusula imposta pela Lei de Terras de 1850, a qual instituiu como única alternativa para a transferência das terras públicas para particulares a venda mediante leilão. O respaldo constitucional à Reforma Agrária nesses termos promoveu a substituição do mecanismo obrigatório do leilão pelo direito de exclusividade dos beneficiários de comprarem as terras que lhes foram designadas pelo Estado, a preços referenciais muito inferiores aos de mercado. Trata-se, pois, de uma política de ordenamento fundiário coerente com o princípio da equanimidade que, em nome da precedência da função social da terra, admite tratamento distinto para sujeitos juridicamente iguais, mas economicamente desiguais.

Pelos critérios constitucionais, essa prerrogativa é extensiva àqueles que tomaram para si terras públicas com até 50 hectares e que as explorem diretamente em regime de agricultura familiar, condições indissociáveis da caracterização da posse. Nisso está a essência e a legitimidade da regularização fundiária.

Em 2009 veio o primeiro atentado a esse primado: a Lei 11.952/2009 passou a considerar como posseiros os que tomaram para si até 1.500 hectares de terras públicas na Amazônia Legal, caindo a exigência da exploração direta, até porque tal extensão de terra não o permitiria. Imediatamente após a sanção da Lei, ato do então presidente Luís Inácio Lula da Silva, a Procuradoria Geral da República impetrou uma Ação Direta de Inconstitucionalidade, a ADI 4269/2009, mas sua ineficácia comprova-se pela mudança do seu texto original para permitir assalto ainda maior às terras públicas.

Doravante, às áreas invadidas antes de 22 de julho de 2008 é estendido o direito de exclusividade de compra, aplicando-se a mesma tabela de preços a que tem direito, os assentados da Reforma Agrária e demais sujeitos da regularização fundiária legítima.

Paradoxalmente, a Lei prescreve a execução judicial aos sujeitos da Reforma Agrária colocados na terra pelo Estado, caso não a paguem 15 anos após a implantação do assentamento. Em contrapartida, sanciona o direito de propriedade aos invasores que controlam terras à revelia da lei, instaurando o benefício da intocabilidade jurídica às posses fictícias, com área que pode ser multiplicada em 50 vezes ao prescrito na Constituição. Como se fosse pouco anui, pela ausência de qualquer prescrição legal, qualquer dimensão adicional em áreas contínuas griladas. 
A grilagem é, portanto, um promissor expediente aos agentes da corrupção endêmica nutrida pelo entrelaçamento entre imunidade política e mando econômico. Isso é o que pode explicar a regularização fundiária em condições idênticas ao prescrito para os posseiros e assentados. O mais perverso ataque à função social enquanto princípio legitimador da transferência do bem comum ao patrimônio privado está na chantagem à compulsoriedade aquisitiva aos que não tem poder de compra e na permissividade aos que o tem em profusão. Mesmo o critério dantes previsto em Lei de o Estado executar investimentos em infraestrutura mínima, como condição prévia de transferência onerosa da terra aos assentados, não resistiu à conjuntura tão propícia ao esbulho.

Inaugura-se, além da desobrigação de qualquer responsabilidade do poder público para com a política de assentamentos, a abertura ao comércio das frações miúdas que só puderam se estabelecer por força do reordenamento fundiário como política pública. A resposta do Estado à segurança jurídica evocada pelo mercado estará sacramentada 10 anos após a alienação onerosa, quando todas as terras concedidas em reforma agrária poderão ser regularmente vendidas. Esse era o risco que os movimentos sociais tentaram afastar: a luta histórica pela imissão, exclusivamente, do direito de uso no âmbito da reforma agrária. Contrariamente, triunfou o direito de troca.

O passivo territorial desta medida se insinua em face do já existente elo entre a mais radical expressão da pobreza, a fome, e o despojo à condição camponesa, expresso na privação do acesso a terra em quantidade suficiente para uma família trabalhar e viver, tendo como horizonte a dignidade e o bem estar. Potencializadas estão as já graves assimetrias no campo, a julgar pelos parâmetros de ordenamento territorial anteriormente válidos, a começar pelo artigo 4 do Estatuto da Terra (Lei 4.504/ 1964) onde se lê:

Para os efeitos desta Lei, definem-se:

II "Propriedade Familiar", o imóvel rural que, direta e pessoalmente explorado pelo agricultor e sua família, lhes absorva toda a força de trabalho, garantindo-lhes a subsistência e o progresso social e econômico, com área máxima fixada para cada região e tipo de exploração, e eventualmente trabalho com a ajuda de terceiros;

III "Módulo Rural", a área fixada nos termos do inciso anterior; 
IV “Minifúndio”, o imóvel rural de área e possibilidades inferiores às da propriedade familiar.

O módulo rural foi concebido como critério aplicável individualmente aos imóveis, segundo variáveis de ordem geográfica, composição familiar e uso do solo. Esse grau de precisão, no entanto, se mostrou administrativamente inaplicável, sobretudo no que diz respeito à tributação. Por essa razão, o módulo acabou substituído pelo critério de módulo fiscal (Lei 6.746/1979), unidade mediana dos módulos rurais de cada município.

O projeto de sociedade indulgente ao latifúndio impõe, necessariamente, a gestão mínima da minifundiarização, a julgar pelo teor da Lei 11.446/2007, derivada de uma Portaria (INCRA, 1997), que alterou o texto do Estatuto da Terra para permitir que o parcelamento para fins de reforma agrária pudesse ignorar o preceito do módulo fiscal. Assim prosperou a divisão do território brasileiro em nove Zonas Típicas de Módulo, admitindo-se partir das especificidades da produção hortigranjeira para fins de titulação aos lotes dos assentamentos de um modo geral. Aliás, essa atividade define o critério limite para a Fração Mínima de Parcelamento.

Nesses termos, o status de imóvel rural juridicamente válido, com escritura e devidamente registrado, pode ser alcançado desde que seja para desenvolver atividades intensivas em trabalho, como o são as atividades hortigranjeiras. Porém, a Fração Mínima de Parcelamento legitimou uma política de assentamentos orientada para um reordenamento, com ponto de partida que é a sua própria negação, a julgar pelo teor do artigo 4 da Lei 4.504/1964, que tipifica a propriedade familiar como

[...] o imóvel rural que, direta e pessoalmente explorado pelo agricultor e sua família, lhes absorva toda a força de trabalho, garantindo-lhes a subsistência e o progresso social e econômico, com área máxima fixada para cada região e tipo de exploração e, eventualmente trabalho com a ajuda de terceiros.

Os limites ao progresso econômico e social, como se pode observar, devem ser explicados à luz da estrutura fundiária, embora os fatores de ordem técnica instruam o consenso em torno do qual são concebidas e implementadas as políticas públicas. Ignorado pelas diretrizes mencionadas, o fator acessibilidade não encontra perdão na geografia: a atividade hortigranjeira impõe a observância da localização. 
Contrariamente ao equacionamento dado, é forçoso reconhecer que na agricultura o fator locacional é determinante da renda diferencial, única variável capaz de promover uma equalização mínima em relação às unidades agrícolas melhor dotadas de terra. Nesses termos, a análise aponta para o paradoxo do ordenamento descolado da produção concreta do território brasileiro, marcado por vazios em termos infraestruturais e de rede urbana, em si concorrentes com abstrações que, mesmo a teoria do Estado Isolado de Johann Heinrich Von Thunen, publicada há quase dois séculos, já conseguia ir além, ao mostrar quão limitante é o fator terra fora dos círculos imediatamente circundantes aos mercados relevantes. Não que se sugira ser suficiente tratar do problema segundo a visão euclidiana da distância enquanto fator absoluto, pois em tempos de império da mercadoria, a necessidade de circulação está colocada.

Concretamente, a insuficiência e a precariedade das estradas rurais é por demais reveladora de um ordenamento alheio aos ativos territoriais inseparáveis das trocas de curto alcance. Para além da relação causa e efeito, Santos (2006) deu evidências suficientes de que às rugosidades correspondem conteúdos, leia-se organização espacial segundo as conveniências dos atores hegemônicos.

Mercados locais são obra dos sujeitos hegemonizados e invisibilizados, para utilizar o referencial do autor, o que não significa correspondente irrelevância em termos econômicos, como atestam Altieri (2012), Oliveira (2003), Rosset (2006), entre outros. A Tabela 1, a seguir, é a melhor expressão da situação de inadequação do ordenamento fundiário à viabilidade econômica do campesinato, considerando que tais atributos são obstáculos inamovíveis.

Tabela 1- Extensão mínima dos imóveis rurais segundo a Zona

Típica de Módulo e o uso do solo predominante

\begin{tabular}{ccccccc}
\hline $\begin{array}{c}\text { Zona Típica de } \\
\text { Módulo (ZTM) }\end{array}$ & $\begin{array}{c}\text { Atividade } \\
\text { hortigranjeira (ha) }\end{array}$ & $\begin{array}{c}\text { Lavoura } \\
\text { Permanente (ha) }\end{array}$ & $\begin{array}{c}\text { Lavoura } \\
\text { Temporária (ha) }\end{array}$ & $\begin{array}{c}\text { Pecuária } \\
\text { (ha) }\end{array}$ & $\begin{array}{c}\text { Florestal } \\
\text { (ha) }\end{array}$ \\
\hline A1 & 2 & 10 & 13 & 30 & 45 \\
\hline A2 & 2 & 13 & 16 & 40 & 60 \\
\hline A3 & 3 & 15 & 20 & 20 & 50 & 60 \\
\hline B1 & 3 & 16 & 25 & 50 & 80 \\
B2 & 3 & 20 & 30 & 60 & 85 \\
B3 & 4 & 25 & 70 & 90
\end{tabular}




\begin{tabular}{cccccc} 
C1 & 4 & 30 & 35 & 90 & 110 \\
C2 & 5 & 35 & 45 & 110 & 115 \\
D & 5 & 40 & 50 & 110 & 120 \\
\hline & & Fonte: (Landau et al., 2013, p. 17).
\end{tabular}

Os parâmetros da Fração Mínima de Parcelamento são suficientemente esclarecedores das razões pelas quais as porções ínfimas de terra comprometem o potencial territorialmente virtuoso do campesinato, mesmo considerando suas modestas demandas fundiárias, em face da lógica de ter na terra a condição para realização do trabalho próprio. Embora a diversificação produtiva seja o que melhor se encaixa a condições objetivas dadas, essa vem sendo cada vez mais tolhida pela monoculturação, que forja dinâmicas territoriais distintas e, não raro, contraproducentes. No entanto, do ponto de vista da acumulação, essa parece ser a única opção à agricultura capitalista, sendo precisamente a redução das contratações a principal meta dos que necessitam de mão de obra externa. Por isso, a opção pelas atividades intensivas em capital, altamente dependentes do trabalho morto retido na tecnologia empregada em máquinas e insumos.

A corrida pela ampliação dos domínios, como forma de compensar a baixa valorização proporcional pela ampliação da escala de produção explica, em parte, o que Almeida (2010) denomina de agroestratégias para explicar a coalização de interesses que respondem pelo açambarcamento ímpar da terra pública no Brasil. Contudo, faz-se necessário acrescentar que os fins produtivos são simbólicos ante o propósito mobilizador dessa escalada: somente o monopólio fundiário investe seus sujeitos da prerrogativa de decidir quando e onde liberar a terra vital para todos, sem exceção. O critério para tanto é a taxa satisfatória de renda capitalizada da terra. Martins (2011) o demonstrou, ao identificar a singularidade do capitalismo rentista brasileiro.

Nisso se encontra a principal explicação para a dramática situação de interdição a terra revelada pelo Sistema Nacional de Cadastro Rural: 65,3\% dos imóveis brasileiros possuíam área inferior a um módulo fiscal em 2011 (INCRA, 2011). Como a área correspondente aos módulos fiscais por município varia entre 5 e 110 hectares, em vista das características físico-territoriais distintas, outra base de dados corroboram-na: de acordo com o último levantamento censitário, 52,8\% das unidades agrícolas brasileiras dispunham de área média de 2,85 hectares (IBGE, 2017). 
Importante lembrar que, nesse caso, não se trata de imóveis rurais necessariamente, porque o IBGE trabalha com a unidade econômica transitória e não com a condição jurídica permanente do domínio. Um estabelecimento será sempre uma fração de terra explorada sob um sistema único de gestão, seja familiar ou corporativo, cabendo aí contratos de arrendamento, parceria, cessão, dentre outros, além obviamente dos imóveis próprios que, de qualquer modo, são a maioria.

Logo, não há nada na Lei 13.465/2017 que expresse indícios mínimos de ruptura possível com essa ordem concentracionista, muito pelo contrário. Não significa, contudo, que tenham sido poucos os que se levantaram contra sua marcha devastadora, expressa em dilapidação ambiental e em vidas ceifadas. A novidade é a intensificação dessa hegemonia, cuja face mais violenta está descrita por Mitidiero Junior (2017, p. 7):

Desde 1985 nunca havia ocorrido tantos conflitos com a presença de atos de violência como em 2016, chegando a cifra de 1.079 ocorrências. Já o dado que personifica a face mais trágica dos conflitos rurais, que são os números de assassinatos, alcançou um total de 61 assassinatos (em média foram 5 assassinatos por mês), o maior número desde 2003 (73 assassinatos) e o segundo maior número nos últimos 25 anos.

A escalada dos conflitos agrários e seu saldo em vítimas coincidem com a morte lenta do Estado de Direito, expressa nos retrocessos legais desde o alvorecer deste milênio, dentre os quais a Lei 13.465/2017 é, por ora, a mais vigorosa. Nos pouco mais de 6 meses de sua gestação, 38 pessoas foram assassinadas em conflitos agrários, não sem a participação de agentes públicos, a exemplo da Chacina da Fazenda Santa Lúcia em Pau d'Arco, perpetrada pela Polícia Militar do Pará e justificada por um mandado judicial de reintegração de posse.

Impõe-se, assim, a reflexão sobre o sentido de num país com pouco mais de 5 milhões de estabelecimentos rurais, frente aos mais de 638 milhões de hectares de estoque fundiário rural, já descontados corpos d'água, áreas urbanizadas, com destinação à conservação ambiental e usufruto indígena (IBGE, 2009), haver uma justiça tão condescendente com saqueadores do solo indispensável aos camponeses, para os quais talvez nada possa restar senão a sina de tentar driblar a indigência, ao preço do encontro com as armas em riste. 


\section{Considerações finais}

Conquistas sociais somente podem ser duradouras quando a política de governo cerceia o poder da força bruta ou do mando econômico e a mediação do Estado reverbera em repactuação dos interesses de classes. Destacaram-se aqui algumas contradições nesse sentido e que culminariam em mais retrocessos do que nossa capacidade de apreendê-los e mesmo de tratá-los nos limites de um texto. De qualquer modo, advoga-se ser esse o desfecho inevitável das alianças que o Partido dos Trabalhadores firmou com setores rentistas, tanto tradicionais quanto emergentes, constituídas em nome da governabilidade que beneficiários tão cevados no fundo público golpeariam na primeira ocasião de oportunidades melhores. Como mostrou Paulino (2014), nesse período ampliaram-se as estratégias de invisibilização do latifúndio, por meio da projeção forjada de uma imagem de pujança econômica associada ao que se convencionou chamar de agronegócio como se sinônimo fosse de agricultura capitalista, mas que não é.

A metamorfose conceitual, ao ser utilizada politicamente, fez com que a cadeia produtiva fosse confundida com setor agropecuário, mais precisamente com o setor empresarial do campo envolvido com a agricultura de escala. Agronegócio, assim, é amplamente representado como o corolário da superioridade técnica, eficiência produtiva e responsabilidade ambiental dos grandes proprietários.

A perspectiva de classe como estratégia de evocação sucedânea de atributos socialmente desejáveis foi aos poucos eliminando a reforma agrária da pauta política nacional, paralelamente ao progresso de mudanças constitucionais que, tão logo sejam concretizadas, atingirão fortemente os territórios indígenas e dos povos tradicionais, tanto quanto as áreas públicas de conservação ambiental, como advertiu Almeida (2010).

Nisso resulta a funcionalidade do golpe parlamentar de 2016. Dentre as provas da conta a ser cobrada em exclusão e violência adicionais, detivemo-nos na MP 759, transformada na Lei aqui analisada, passando ao largo de outra MP: a 726, aprovada no dia 26 de maio de 2017 pelo Senado da República.

Celeridade do trâmite e conteúdo similar são suas marcas comuns. A MP 726 reduzia em 37\% a unidade de conservação da Floresta Nacional do Jamanxim, no Pará; também reduzia em 20\% o Parque Nacional de São Joaquim, a segunda área de maior visitação em Santa Catarina e santuário 
de algumas espécies em extinção, dentre elas a onça parda e o lobo guará. Mesmo o veto integral pelo Presidente da República em 19 de junho não resultará em arquivamento da matéria, pois se trata de decisão movida por óbices jurídicos de conteúdo e de apreciação. De acordo com as palavras do Ministro do Meio Ambiente, ela voltará ao parlamento como "urgência constitucional" (Uribe; Maisonnave; Watanabe, 2017).

De qualquer modo, a Lei 13.465/2017 sobre a qual versa este texto é, no momento, o maior atentado à Constituição brasileira, pois permite ampla legalização da grilagem das terras públicas. O direito de propriedade, por meio da compra sem licitação e a preços referenciais módicos, se estenderá a todas as áreas públicas com até 2.500 hectares invadidas, mas tratadas como posse. A Constituição Brasileira define em 50 hectares o limite máximo, mas o caminho já havia sido aberto em 2009 com a titulação de grilos com até 1.500 hectares na Amazônia Legal, conforme mencionado. Nem mesmo uma Ação Direta de Inconstitucionalidade pode se impor às prioridades de um Poder Judiciário assoberbado com demandas de diferentes grandezas, dentre elas as provenientes da grilagem. Os ruralistas ficaram, pois, à vontade para ampliar em 1.000 hectares a fração regularizável do patrimônio mais fundamental de uma sociedade: as terras de domínio comum.

Tamanha desfaçatez no trato com a coisa pública foi potencializada com a Planilha Referencial de Preços para Terra Nua, aprovada pela Portaria 199, de 30 de março deste ano (INCRA, 2017). A Recomendação 01/2017 do Ministério Público Federal (Brasil, 2017c) identifica correlação da mesma com a MP 759/2016 para favorecer o enriquecimento ilícito, paralelamente à destruição dos preceitos da justiça fundiária a que toda política de ordenamento fundiário está submetida por força constitucional. Segundo o Coordenador do Grupo Terras da Procuradoria Geral da República (Brasil, 2017c), houve expresso atentado ao princípio da isonomia em prejuízo dos beneficiários da reforma agrária, mediante manipulação das condições e dos preços da terra para regularização fundiária.

Municípios como o de Sinop e de Primavera do Leste em Mato Grosso foram destacados pelo fato de os valores terem sido reduzidos drasticamente, permitindo a regularização das terras por menos de um centesimo do valor de mercado. O procurador recomendou a não aplicação da Lei 13.465/2017, sob pena de imputação de medidas administrativas e judiciais aos responsáveis, pois em suas palavras: 
[...] a expansão das áreas de fronteira acarretará o incremento de conflitos agrários (com consequente aumento das mortes associadas), do desmatamento (com afetação das metas celebradas no Acordo de Paris) e ampliação das situações de completo desrespeito à legislação (Brasil, 2017c, p. 15).

O imbróglio jurídico certamente não será suficiente para deter os verdadeiros invasores de terra, suplementarmente beneficiados desde o golpe parlamentar que tirou o Partido dos Trabalhadores do poder. Não obstante, considera-se que Luís Inácio Lula da Silva fora um aliado singular e imprescindível, pois sua política foi orientada para o ataque à capacidade de controle social construída às duras penas no último meio século, mediante repressão, cooptações e concessões miúdas, devidamente descritas por Singer (2012).

Mas no seio da lógica rentista com a qual opera o capitalismo, a dilatação em 50 vezes do limite regularizável de terras públicas é um dentre os atos de demolição de um projeto de justiça social mínima para o Brasil, a exemplo da extinção do Ministério do Desenvolvimento Agrário, a migalha que por 17 anos coubera ao campesinato por força do enfrentamento resiliente, mas desigual, ao Estado do latifúndio.

Importante reconhecer que, tanto quanto na ciência e em segmentos da sociedade civil organizada, não há aquiescência unânime em favor dos saqueadores do futuro, apenas superioridade na capacidade de amealhar dinheiro para comprar votos, sentenças e vidas, como se vê a cada dia. Por ora o governo, tanto quanto o parlamento mais latifundista e mais denunciado na justiça por crimes de corrupção, está por demais ocupado em garantir aos seus iguais, e o quanto antes, todos os despojos da infante democracia.

Nota

1 Pesquisa apoiada financeiramente pelo Conselho Nacional de Desenvolvimento Científico e Tecnológico, processo 308147/2016-2, vigência: janeiro de 2017 a dezembro de 2019.

\section{Referências}

ALMEIDA, A. W. B. Capitalismo globalizado e recursos territoriais. Rio de Janeiro: Lamparina, 2010. 
ALTIERI, M.A et al. Agroecologically efficient agricultural system for smallholder farmers: contributions to food sovereignty. Agron. Sustain. Dev., n. 32, p. 1-13, 2012.

BRASIL. ADI 4269 (2009a). Ação Direta de Inconstitucionalidade. Brasília, 09 jul. 2009. Disponível em: <http://www.stf.jus.br/portal/processo/verProcessoAndamento.asp?numero $=4269 \&$ classe $=$ ADI\&origem $=$ AP\&recurso $=0 \&$ tipoJulg amento=M>. Acesso em: 04 jun. 2017. $\overline{1} \overline{9} \overline{8} \overline{.}$

. Constituição da República Federativa do Brasil. São Paulo: Saraiva,

. Lei do Estatuto da Terra (1964). Lei no 4.504, de 30 de novembro de 1964. Dispõe sobre o Estatuto da Terra, e dá outras providências. Diário Oficial [da] República Federativa do Brasil, Brasília, DF, 30 nov. 1964.

. Lei 6.746, de 10 de dezembro de 1979. Altera o disposto nos artigos 49 e 50 da Lei 4.504, de 30 de novembro de 1964, e dá outras providências. Diário Oficial da União, Brasília, DF, 11 dez. 1979.

. Lei 8.629, de 25 de fevereiro de 1993. Dispõe sobre a regulamentação dos dispositivos constitucionais relativos à reforma agrária, previstos no Capítulo III, Título VII, da Constituição Federal. Diário Oficial da União, Brasília, DF, 26 fev. 1993.

Lei 11.446, de 5 de janeiro de 2007. Altera a Lei 4.504, de 30 de novembro de 1964, dispondo sobre parcelamentos de imóveis rurais, destinados à agricultura familiar, promovidos pelo Poder Público. Diário Oficial da União, Brasília, DF, 6 jan. 2007.

Lei da Regularização Fundiária da Amazônia Legal (2009b). Lei 11.952, de 25 de junho de 2009. Dispõe sobre a regularização fundiária das ocupações incidentes em terras situadas em áreas da União, no âmbito da Amazônia Legal; altera as Leis nos 8.666, de 21 de junho de 1993, e 6.015, de 31 de dezembro de 1973; e dá outras providências. Diário Oficial da União, Brasília, DF, 26 jun. 2009.

. Lei da Regularização Fundiária Rural e Urbana (2017a). Lei 13.465, de 11 de julho de 2017. Dispõe sobre a regularização fundiária rural e urbana, sobre a liquidação de créditos concedidos aos assentados da reforma agrária e sobre a regularização fundiária no âmbito da Amazônia Legal; institui mecanismos para aprimorar a eficiência dos procedimentos de alienação de imóveis da União; altera diversas Leis e dá outras providências. Diário Oficial da União, Brasília, DF, 13 jul. 2017.

. Ministério Público da União. Nota Técnica n. 01/2017 (2017b). Grupo de Trabalho Terras Públicas e Desapropriação. Disponível em: <http://www.mpdft. $\mathrm{mp} . \mathrm{br} / \mathrm{portal} / \mathrm{pdf} /$ noticias/abril_2017/Nota_T\%C3\%A9cnica_MP_759-2016_ PROURB.pdf>. Acesso em: 01 juñ. 2017.

. Ministério Público Federal. Recomendação PGR 01/2017 (2017c). Registro P $\overline{G R}-00234057$ de 12 de julho de 2017. Disponível em: <http://www.mpf.mp.br/ pgr/documentos/1_2017_Recomendacao_GT_Terras.pdf>. Acesso em: 16 jul. 2017. 
Tribunal de Contas da União. Acórdão TCU 000.517/2016-O (2016). Disponível em: <http://portal.tcu.gov.br/lumis/portal/file/fileDownload.jsp?file $\mathrm{Id}=8 \mathrm{~A} 8182 \mathrm{~A} 157532457015753275 \mathrm{~B} 2 \mathrm{~F} 1523 \&$ inline=1>. Acesso em: 25 jul. 2017.

IBGE. Instituto Brasileiro de Geografia e Estatística. Censo Agropecuário 2006: Brasil, Grandes Regiões e Unidades da Federação. Rio de Janeiro: IBGE, 2009.

. Sistema IBGE de Recuperação Automática - SIDRA: Banco de Dados Agregados. 2017. Disponível em: < http://www2.sidra.ibge.gov.br >. Acesso em: 30 maio 2017.

INCRA. Instituto Nacional de Colonização e Reforma Agrária. Portaria 36 de 26 de agosto de 1997. Estabelece as Zonas Típicas de Módulo e estende a Fração Mínima de Parcelamento para os municípios. Brasília: INCRA, 1997.

. Portaria 199 de 30 de março de 2017. Aprova a Instrução Normativa 87 que institui a Planilha de Preços Referenciais para fins de titulação. Brasília: INCRA, 2017.

. Sistema Nacional de Cadastro Rural: estatísticas cadastrais - situação jurídica apurada em 2011. Brasília: INCRA, 2011. Não publicado.

. Sistema Nacional de Cadastro Rural: Módulos Fiscais dos municípios brasileiros - Índices Básicos de 2013. 2013. Disponível em: <http://www.incra. gov.br/sites/default/files/uploads/estrutura-fundiaria/regularizacao-fundiaria/ indices-cadastrais/indices_basicos_2013_por_municipio.pdf. Acesso em: 12 jul. 2017.

LANDAU, E. C. et al. Geoespacialização de Indicadores Cadastrais Rurais do Brasil. Sete Lagoas: Embrapa, 2013.

MARÉS, C. F. A função social da terra. Porto Alegre: Fabris, 2003.

MARTINS, J. S. A política no Brasil: lúmpen e místico. São Paulo: Contexto, 2011.

MARX, K. O capital. Rio de Janeiro: Civilização Brasileira, 1974. v. 6 (Livro 3). MITIDIERO JUNIOR, M. A. Violência no campo brasileiro em tempos de golpe. Boletim Dataluta, Presidente Prudente, n. 114, p. 1-23, jun. 2017. Disponível em: $<$ http://www2.fct.unesp.br/nera/artigodomes/6artigodomes_2017.pdf >. Acesso em: 28 jun. 2017.

OLIVEIRA, A. U. Barbárie e Modernidade: as transformações no campo e o agronegócio no Brasil. Terra Livre, São Paulo, n. 21, p. 113-156, 2003.

PAULINO, E. T. The agricultural, environmental and socio-political repercussions of Brazil's land governance system. Land Use Policy, n. 36, p. 134144, 2014. https://doi.org/10.1016/j.landusepol.2013.07.009.

ROSSET, P. Alternativa à política fundiária de mercado. In: SAUER, S.; PEREIRA, J. M. (Org.). Capturando a terra. São Paulo: Expressão Popular, 2006. p. 315-341.

SANTOS, M. A natureza do espaço. 4. ed. São Paulo: Edusp, 2006.

SINGER, A. Os sentidos do lulismo. São Paulo: Companhia das Letras, 2012.

TALASKA, A. Ainda existem latifúndios no Brasil? Santa Cruz do Sul: Edunisc, 2016. 
URIBE, G.; MAISONNAVE, F.; WATANABE, P. Temer veta corte de floresta no Pará, mas vai propor lei com nova redução. Folha de S. Paulo, São Paulo, 19 jun. 2017. Disponível em: < http://www1.folha.uol.com.br/ambiente/2017/06/1894045sob-pressao-temer-veta-proposta-de-reducao-de-area-florestal-no-para.shtml>. Acesso em: 20 jun. 2017.

Eliane Tomiasi Paulino - possui graduação, mestrado e doutorado em Geografia pela Universidade Estadual Paulista Júlio de Mesquita Filho. Pós-Doutorado pelo Programa de Estudios delDesarrollo, da Universidad Autónoma de Zacatecas, México e pelo International Development Studies, da Saint Mary's University, Halifax, Canadá. Atualmente é docente dos cursos de graduação e de pós-graduação em Geografia da Universidade Estadual de Londrina.

Recebido para publicação em 20 de julho de 2017 Aceito para publicação em 12 de setembro de 2017 